\title{
Medication transitions and polypharmacy in older adults following acute care
}

This article was published in the following Dove Press journal:

Therapeutics and Clinical Risk Management

19 March 2014

Number of times this article has been viewed

\section{John-Michael Gamble ${ }^{1, *}$ \\ jill J Hall ${ }^{2, *}$ \\ Thomas J Marrie ${ }^{3}$ \\ Cheryl A Sadowski \\ Sumit R Majumdar ${ }^{4}$ \\ Dean T Eurich ${ }^{5}$}

'School of Pharmacy, Memorial University of Newfoundland,

St John's, NL, ${ }^{2}$ Faculty of Pharmacy and Pharmaceutical Sciences, University of Alberta, Edmonton, AB, ${ }^{3}$ Faculty of Medicine, Dalhousie University, Halifax, NS, ${ }^{4}$ Faculty of Medicine and Dentistry, ${ }^{5}$ School of Public Health, University of Alberta, Edmonton, AB, Canada

*These authors contributed equally to this work

Video abstract

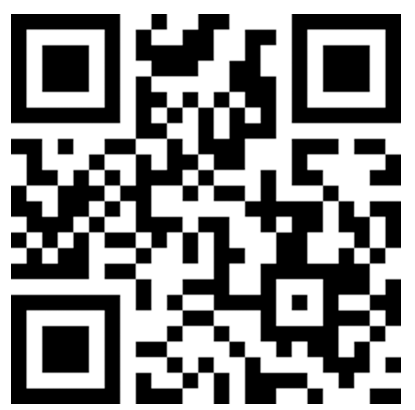

Point your SmartPhone at the code above. If you have a QR code reader the video abstract will appear. Or use: http://dvpr.es/lfXmvKR

Correspondence: Dean T Eurich School of Public Health, 2-040 Li Ka Shing CHRI, University of Alberta, II 6th Street and 85th Avenue, Edmonton, AB T6G 2EI, Canada $\mathrm{Tel}+\mathrm{I} 7804926333$

Fax +I 7804927455

Email deurich@ualberta.ca
Background/objective: Medication changes at transitions of care and polypharmacy are growing concerns that adversely impact optimal drug use. We aimed to describe transitions and patterns of medication use before and 1 year after older patients were hospitalized for communityacquired pneumonia, the second-most common reason for admission in North America.

Materials and methods: This was an analysis of a population-based clinical registry of patients treated in any of the six hospitals or seven emergency departments in Edmonton, Alberta, Canada, comprising 2,105 patients 65 years and older with community-acquired pneumonia who had survived at least 1 year. The prevalence of polypharmacy (five or more unique prescription drugs), as well as new use and persistence of common drug classes were assessed.

Results: The mean age was 78 years (standard deviation 8 years), $50 \%$ were female, $62 \%$ were hospitalized, and 58\% had severe pneumonia. Among the 2,105 patients, $949(45 \%)$ were using five or more medications prior to hospitalization, increasing to $1,559(74 \%)$ within 90 days postdischarge and remaining over $70 \%$ at 1 year. Overall, 1,690 (80\%) patients newly started and 1,553 (74\%) patients stopped at least one medication in the first 90 days of follow-up. The prevalence of the most common drug classes (ie, cardiovascular, alimentary/metabolism) remained stable, with the exception of anti-infective agents, whereby $25 \%$ of patients were dispensed an anti-infective agent 3 months to 1 year after hospitalization.

Conclusion: Most older patients with pneumonia are subject to polypharmacy, and almost every patient had a medication started or stopped during 1-year follow-up, with $25 \%$ using antibiotics again. The period following an episode of pneumonia represents an opportunity potentially to optimize pharmacotherapy.

Keywords: polypharmacy, drug utilization, elderly, community-acquired pneumonia, pharmacoepidemiology

\section{Introduction}

Community-acquired pneumonia (CAP) is recognized as the second-most common reason for hospitalization and a leading cause of morbidity and mortality that tends to disproportionately affect older ( $\geq 65$ years) adults. ${ }^{1}$ Indeed, older patients are at particularly high risk for CAP, due to the clustering of multiple comorbid chronic conditions, and each year in the US there are approximately 900,000 episodes of CAP, with approximately $40 \%$ requiring hospitalization, and close to 50,000 pneumoniarelated deaths. ${ }^{2,3}$

It is increasingly recognized that the acute management of many diseases, including CAP, results in numerous medication changes during transitions of care. ${ }^{4}$ Studies have shown that although often deliberate, many unintended medication discrepancies 
occur at the time of admission and are often carried through to discharge..$^{5}$ Moreover, medications are frequently initiated and may or may not be intentionally prescribed at discharge. ${ }^{6}$ The impact of unintentional discontinuation of medications and new starts during transitions of care include adverse effects, drug interactions, rehospitalization, and other effects of under- or overtreatment. ${ }^{6-10}$

Furthermore, the potential impact of medication changes during transition of care may be more pronounced in older patients due to the use of multiple medications, or polypharmacy. Indeed, approximately a third of older adults in the US use five or more prescription medications concurrently, with some reports suggesting rates as high as $40 \%-80 \%$ among those 65 years and older. ${ }^{11-16}$ Importantly, polypharmacy is associated with an increased risk of frailty, disability, falls, poor adherence, hospitalization, drug-drug interactions, adverse drug events, and mortality., ${ }^{4,17-21}$

Identifying populations at risk of suboptimal medication use and at high risk of adverse drug events is important for understanding who and when to target those individuals' medication profiles for optimization of drug therapies. Because CAP is so common, particularly in older patients who are already subject to polypharmacy, this represents a population at particularly high risk of potentially preventable adverse drug events. Therefore, we aimed to describe transitions and patterns of medication use before and 1 year after an episode of CAP among older patients.

\section{Materials and methods Subjects and setting}

For 2 years (2000-2002), all patients over 17 years of age with CAP admitted to all six hospitals or presenting to any of the seven emergency departments in Edmonton, Alberta, Canada were enrolled in a population-based clinical registry. These six hospitals and one freestanding emergency department serve a population of approximately 1 million people, whereby all services are covered under a universal health care insurance plan. Details of the population-based clinical registry and prospective data-collection methods have been previously described for both inpatient and outpatient cohorts. ${ }^{22,23}$ Briefly, a standardized and previously validated clinical CAP-management pathway was implemented for all patients presenting to the hospital or emergency department with two or more signs or symptoms of CAP (productive or nonproductive cough, pleuritic chest pain, shortness of breath, temperature $>38^{\circ} \mathrm{C}$, crackles on auscultation) and radiographic evidence of pneumonia. Patients were excluded if they had tuberculosis or cystic fibrosis, were immunocompromised, or were pregnant.
Trained research nurses prospectively collected data using standardized abstraction forms recording demographic data, detailed physician-confirmed clinical data, and selfreported prescription medication use within the week prior to admission (verified by health professionals and research nurses and as documented within the medical chart). In addition, a validated measure of disease-specific severity, the pneumonia severity index, was collected. ${ }^{24}$ Long-term follow-up of prescription-drug data was acquired from the administrative drug databases of Alberta Blue Cross and based on previously validated claims data, ${ }^{25}$ with data linkage obtained through deidentified unique personal health care numbers. ${ }^{23,26}$ This study was approved by the research ethics board at the University of Alberta.

\section{Study sample}

We restricted our study sample to subjects aged 65 years and older, because this is a population at particularly high risk of adverse drug events ${ }^{27}$ and because prescription medication use is captured for all patients 65 years and older within the province. Furthermore, we excluded subjects that died in hospital or within 1 year postdischarge from the hospital or emergency department to allow for the full characterization of medication use following CAP treatment. Therefore, all subjects were followed for a minimum of 365 days following discharge and were alive to receive postdischarge prescriptions.

\section{Medication-related definitions and outcomes}

We defined polypharmacy as the concurrent use of five or more medications. This definition of polypharmacy has been used in numerous other publications, ${ }^{4,16-18}$ and has been shown to be associated with several important adverse events in older adults. ${ }^{18}$ We measured polypharmacy and medication use at baseline (1 week prior to CAP episode) and then in 90-day intervals (0-90 days', 91-180 days', 181-270 days', and 271-365 days' follow-up) for 1 year following a patient's initial CAP episode during the study period. To test the sensitivity of our results to our cutoff point of five or more medications used to define polypharmacy, we varied our definition to include the concurrent use of seven or more and ten or more unique medications.

\section{Statistical analysis}

Baseline characteristics of the study sample are described using means and standard deviation (SD) or numbers and proportions where appropriate. We measured the number 
and percentage (compared to baseline) of subjects starting and stopping medications within the most prevalent therapeutic classes. In an effort to avoid difficult-to-interpret and unwieldy comparisons and descriptions, we focused our analysis on describing trends over time for only the most common therapeutic classes, defined as Anatomical Therapeutic Chemical classification system level 1 groups $^{28}$ with $>20 \%$ prevalence at baseline. Analyses were further stratified by age-group (65-74, 75-84, and 85 years and older). We used generalized estimating equations to account for repeated measures and the longitudinal structure of our data. We assumed an exchangeable correlation structure. We specifically tested for changes in medication use over time using an ordinal dummy variable for each period (baseline as reference period) as our independent variable. We considered a $10 \%$ absolute change between time periods to indicate a clinically meaningful difference in drug use over time. All analyses were conducted using Stata/SE version 11.0 (StataCorp LP, College Station, TX, USA).

\section{Results}

\section{Subject characteristics}

There were 3,187 older patients with CAP who were either hospitalized $(2,128[67 \%])$ or seen in an emergency department $(1,059$ [33\%]) during our study. We excluded $143(<5 \%)$ without linkable follow-up data, $278(9 \%)$ who died in hospital, and $661(21 \%)$ who died within 1 year of discharge. Of the 2,105 subjects included in our final study sample, the mean age was 78 (SD 8) years, $50 \%$ were female, and $62 \%$ were admitted to the hospital (Table 1). Most (91\%) subjects were independently mobile. The most common comorbidities were cardiovascular disease (includes myocardial infarction, coronary disease, heart failure, and peripheral vascular disease), chronic obstructive pulmonary disease, mental illness, stroke, cancer, and chronic kidney disease. Fifty-eight percent of subjects were classified as having severe pneumonia based on the pneumonia severity index (class IV and V).

\section{Medication use at baseline}

The mean number of medications used was 4.5 (SD 2.8), with $45 \%$ of the cohort using five or more medications at baseline. The most common medication classes (as defined by the Anatomical Therapeutic Chemical classification system) with a prevalence greater than $20 \%$ used at baseline were cardiovascular agents $(n=1,322[63 \%])$, alimentary tract and metabolism agents $(n=1,034[49 \%])$, nervous system agents $(n=966[47 \%])$, respiratory agents $(n=803$ [38\%]), blood and blood-forming agents $(n=632$ [30\%]), and
Table I Cohort characteristics of 2,105 subjects over age 65 years with community-acquired pneumonia who were hospitalized or presented to the emergency room

\begin{tabular}{|c|c|c|}
\hline Characteristics & & \\
\hline Age, years, mean, SD & 78 & 8 \\
\hline $65-74$ years, $n$ & 784 & $37 \%$ \\
\hline $75-85$ years, $n$ & 886 & $42 \%$ \\
\hline 85 years and older, $n$ & 435 & $21 \%$ \\
\hline Females, $\mathrm{n}$ & 1,060 & $50 \%$ \\
\hline \multicolumn{3}{|l|}{ Previous comorbidities, $\mathrm{n}$} \\
\hline Cerebrovascular disease & 278 & $13 \%$ \\
\hline Heart disease & 1,069 & $51 \%$ \\
\hline Neoplasm & 251 & $12 \%$ \\
\hline Renal disease & 205 & $10 \%$ \\
\hline COPD & 642 & $30 \%$ \\
\hline Mental illness & 278 & $13 \%$ \\
\hline \multicolumn{3}{|l|}{ Pneumonia severity index, $\mathrm{n}$} \\
\hline Class I and II & 269 & $13 \%$ \\
\hline Class III & 619 & $29 \%$ \\
\hline Class IV & 932 & $44 \%$ \\
\hline Class V & 285 & $14 \%$ \\
\hline \multicolumn{3}{|l|}{ Premorbid functional status, $\mathrm{n}$} \\
\hline Independent mobility & 1,918 & $91 \%$ \\
\hline Wheelchair/prosthesis & 122 & $6 \%$ \\
\hline Bedridden & 65 & $3 \%$ \\
\hline \multicolumn{3}{|l|}{ Smoking status, $\mathrm{n}$} \\
\hline Nonsmokers & 1,169 & $56 \%$ \\
\hline Former smoker & 631 & $30 \%$ \\
\hline Current smokers & 305 & $14 \%$ \\
\hline Nursing home residents, $\mathrm{n}$ & 310 & $15 \%$ \\
\hline Number of medications at baseline, mean, SD & 4.5 & 2.8 \\
\hline Five or more medications, $\mathrm{n}$ & 949 & $45 \%$ \\
\hline
\end{tabular}

Abbreviations: SD, standard deviation; COPD, chronic obstructive pulmonary disease.

general anti-infective agents for systemic use ( $\mathrm{n}=435$ [21\%]) (Table 2). Angiotensin-converting enzyme inhibitors and angiotensin-receptor blockers, followed by diuretics, were the most common cardiovascular agents used. Proton-pump inhibitors, oral diabetes agents, and histamine-receptor blockers accounted for over half the use of alimentary tract and metabolism agents. Antidepressants were the most commonly used class of nervous system agents, and inhaled agents accounted for over $90 \%$ of respiratory agents.

\section{Medication use during follow-up}

The number of subjects with polypharmacy increased from $949(45 \%)$ at baseline to $1,559(74 \%)$ in the 90 -day period following the episode of CAP. The prevalence of polypharmacy remained stable throughout the remainder of the follow-up period, with $73 \%$ of patients remaining on five or more medications at the end of 1 year (Figure 1). Even when antibiotic use was excluded, the prevalence of polypharmacy remained similar: $42 \%$ at baseline, $70 \%$ within 90 days, 
Table 2 Prevalence of drug classes and number of medications utilized by 2,105 subjects over age 65 years with community-acquired pneumonia discharged from hospital or the emergency department

\begin{tabular}{|c|c|c|c|c|c|c|c|c|c|c|}
\hline \multirow{2}{*}{$\begin{array}{l}\text { Anatomical therapeutic } \\
\text { chemical class } \\
\text { Cardiovascular system }\end{array}$} & \multicolumn{2}{|c|}{ Baseline, $\mathbf{n}$} & \multicolumn{2}{|c|}{$\begin{array}{l}\text { 0-90 days' } \\
\text { follow-up, } n\end{array}$} & \multicolumn{2}{|c|}{$\begin{array}{l}91-180 \text { days' } \\
\text { follow-up, } n\end{array}$} & \multicolumn{2}{|c|}{$\begin{array}{l}\text { I8I-270 days' } \\
\text { follow-up, } n\end{array}$} & \multicolumn{2}{|c|}{$\begin{array}{l}27 I-365 \text { days' } \\
\text { follow-up, } n\end{array}$} \\
\hline & $\mathrm{I}, 322$ & $63 \%$ & $\mathrm{I}, 253$ & $60 \%$ & 1,217 & $58 \%$ & $|, 2| I$ & $58 \%$ & 1,218 & $58 \%$ \\
\hline Renin-angiotensin system agents & 499 & $24 \%$ & 739 & $35 \%$ & 734 & $35 \%$ & 742 & $35 \%$ & 757 & $36 \%$ \\
\hline Beta-blockers & 225 & $11 \%$ & 330 & $16 \%$ & 319 & $15 \%$ & 314 & $15 \%$ & 340 & $16 \%$ \\
\hline Calcium-channel blockers & 146 & $7 \%$ & 371 & $18 \%$ & 359 & $17 \%$ & 365 & $17 \%$ & 367 & $17 \%$ \\
\hline Diuretics & 625 & $30 \%$ & 700 & $33 \%$ & 619 & $29 \%$ & 633 & $30 \%$ & 636 & $30 \%$ \\
\hline Nitrates & 187 & $9 \%$ & 213 & $10 \%$ & 203 & $10 \%$ & 199 & $9 \%$ & 208 & $10 \%$ \\
\hline Lipid-lowering agents & 276 & $13 \%$ & 317 & $15 \%$ & 322 & $15 \%$ & 323 & $15 \%$ & 350 & $17 \%$ \\
\hline Alimentary tract and metabolism & $\mathrm{I}, 034$ & $49 \%$ & 924 & $44 \%$ & 848 & $40 \%$ & 851 & $40 \%$ & 849 & $40 \%$ \\
\hline Proton-pump inhibitors & 314 & $15 \%$ & 438 & $21 \%$ & 427 & $20 \%$ & 429 & $20 \%$ & 446 & $21 \%$ \\
\hline $\mathrm{H}_{2}$-receptor blockers & 88 & $4 \%$ & 88 & $4 \%$ & 72 & $3 \%$ & 77 & $4 \%$ & 65 & $3 \%$ \\
\hline Oral diabetes agents & 261 & $12 \%$ & 229 & $11 \%$ & 230 & $11 \%$ & 224 & $11 \%$ & 224 & $11 \%$ \\
\hline Nervous system & 996 & $47 \%$ & 935 & $44 \%$ & 872 & $41 \%$ & 843 & $40 \%$ & 876 & $42 \%$ \\
\hline Antipsychotics & 47 & $2 \%$ & 76 & $4 \%$ & 72 & $3 \%$ & 66 & $3 \%$ & 76 & $4 \%$ \\
\hline Antidepressants & 328 & $16 \%$ & 358 & $17 \%$ & 350 & $17 \%$ & 332 & $16 \%$ & 351 & $17 \%$ \\
\hline Anxiolytics & 193 & $9 \%$ & 304 & $14 \%$ & 280 & $13 \%$ & 266 & $13 \%$ & 272 & $13 \%$ \\
\hline Hypnotics/sedatives & $24 I$ & $11 \%$ & 289 & $14 \%$ & 252 & $12 \%$ & 267 & $13 \%$ & 265 & $13 \%$ \\
\hline Respiratory system & 803 & $38 \%$ & 859 & $41 \%$ & 697 & $33 \%$ & 688 & $33 \%$ & 660 & $31 \%$ \\
\hline Inhaled & 732 & $35 \%$ & 721 & $34 \%$ & 656 & $31 \%$ & 642 & $30 \%$ & 607 & $29 \%$ \\
\hline Blood and blood-forming organs & 632 & $30 \%$ & 368 & $17 \%$ & 341 & $16 \%$ & 370 & $18 \%$ & 375 & $18 \%$ \\
\hline $\begin{array}{l}\text { General anti-infectives for } \\
\text { systemic use }\end{array}$ & 435 & $21 \%$ & 1,142 & $54 \%$ & 500 & $24 \%$ & 491 & $23 \%$ & 534 & $25 \%$ \\
\hline $\begin{array}{l}\text { Systematic hormonal preparations, } \\
\text { excluding sex hormones }\end{array}$ & 397 & $19 \%$ & 593 & $28 \%$ & 490 & $23 \%$ & 480 & $23 \%$ & 500 & $24 \%$ \\
\hline Musculoskeletal system & 359 & $17 \%$ & 524 & $25 \%$ & 486 & $23 \%$ & 496 & $24 \%$ & 502 & $24 \%$ \\
\hline NSAIDs & 351 & $17 \%$ & 293 & $14 \%$ & 252 & $12 \%$ & 249 & $12 \%$ & 240 & $11 \%$ \\
\hline $\begin{array}{l}\text { Genitourinary system and sex } \\
\text { hormones }\end{array}$ & 124 & $6 \%$ & 285 & $14 \%$ & 263 & $12 \%$ & 278 & $13 \%$ & 257 & $12 \%$ \\
\hline Dermatologicals & 98 & $5 \%$ & 193 & $9 \%$ & 228 & $11 \%$ & 219 & $10 \%$ & 217 & $10 \%$ \\
\hline Immunomodulating agents & 13 & $1 \%$ & 21 & $1 \%$ & 20 & $1 \%$ & 19 & $1 \%$ & 18 & $1 \%$ \\
\hline Mean number (SD) of medications & \multicolumn{2}{|c|}{$4.5(2.8)$} & \multicolumn{2}{|c|}{$6.8(4.0)$} & \multicolumn{2}{|c|}{$6.3(3.8)$} & \multicolumn{2}{|c|}{$6.4(3.9)$} & \multicolumn{2}{|c|}{$6.6(4.0)$} \\
\hline $\begin{array}{l}\text { Subjects with polypharmacy } \\
\text { (five or more unique medications) }\end{array}$ & 949 & $45 \%$ & 1,559 & $74 \%$ & 1,502 & $71 \%$ & 1,519 & $72 \%$ & $\mathrm{I}, 540$ & $73 \%$ \\
\hline
\end{tabular}

Abbreviations: NSAIDs, nonsteroidal anti-inflammatory drugs; SD, standard deviation.

and $72 \%$ at study end. Using a cutoff point of seven or more medications (23\% baseline, 56\% 90 days, 57\% 365 days) or ten or more medications (5\% baseline, 36\% 90 days, 39\% 365 days) indicated that the prevalence of polypharmacy increased even with more stringent definitions. We did not observe any absolute differences of $10 \%$ or greater in the prevalence of polypharmacy between the various age-groups (Figure 1).

Overall, the use of the most prevalent medication classes remained stable over time (Table 2 and Figure 2). As expected, the use of antibiotics increased substantially following discharge (33\% absolute increase, $P<0.001)$ compared to the 1 week prior to presentation. Of the 1,142 subjects that had been dispensed an anti-infective agent between 0 and 90 days post-discharge, 34\% were prescribed betalactams (penicillins, cephalosporins, carbapenems, etc), 20\% macrolides, and 72\% quinolones (not mutually exclusive).
We considered that "any" antibiotic use within 90 days of pneumonia was related to the index episode of pneumonia. But antibiotic use remained elevated after 90-days over the course of follow-up, and in particular we noted increased new (ie, non-index event pneumonia-related) antibiotic use between 3 months and 1 year (Figure 3). Postpneumonia, the most common antibiotics prescribed were quinolones (13\%), followed by beta-lactams $(8 \%)$ and macrolides $(6 \%)$.

\section{New starts and stops of medications}

The mean number of new medications started in the first 90 days of follow-up was 3.3 medications (SD 2.7). There were $1,690(80 \%)$ patients who started at least one new medication class that they did not report receiving at baseline. The most common medication classes started over the 1 year postdischarge period were anti-infective agents, musculoskeletal agents, dermatological agents, nervous system agents, 


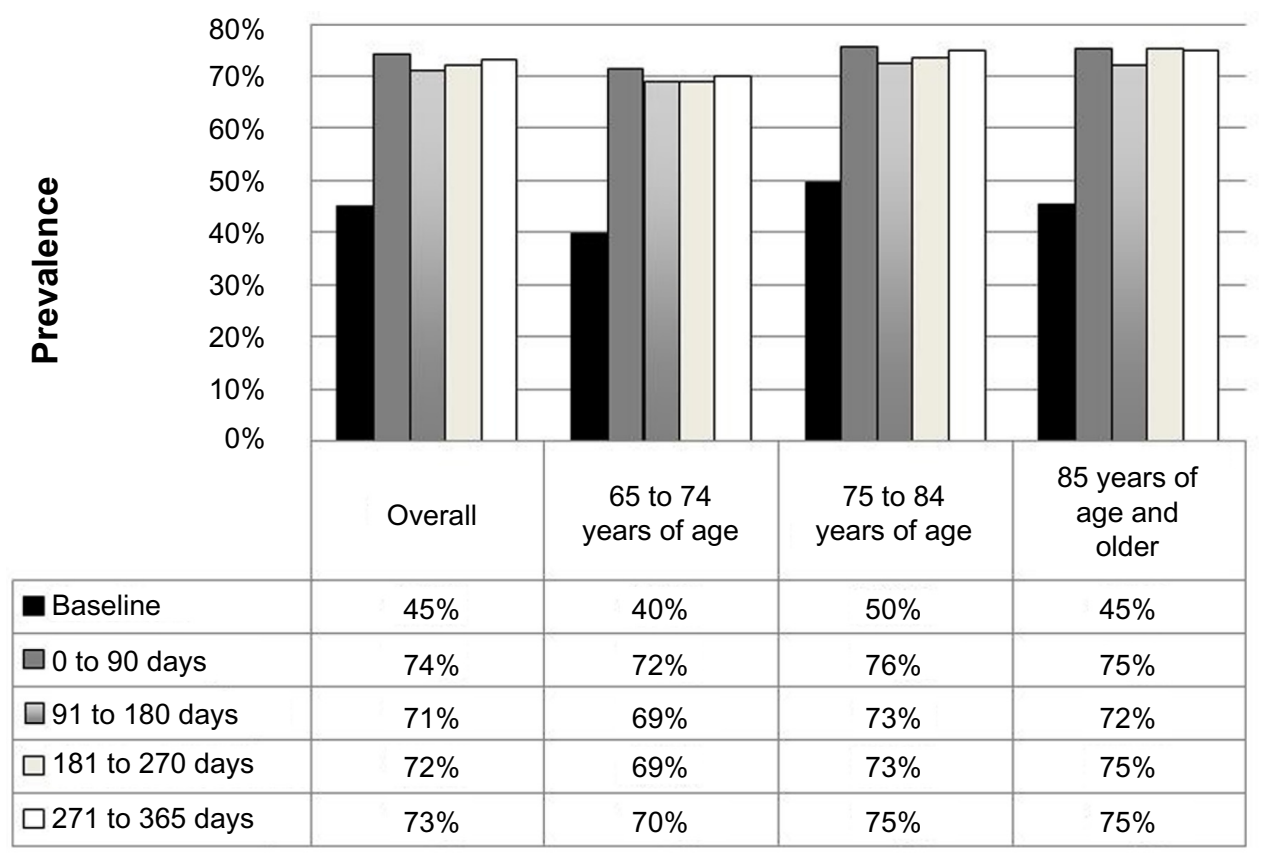

Figure I Polypharmacy over time for 2,105 patients with community-acquired pneumonia, stratified by age.

systematic hormones, alimentary tract and metabolism agents, and respiratory agents, in order of prevalence. In contrast, the mean number of medications discontinued was $2.4(\mathrm{SD}=2.6)$ in the first 90 days of follow-up. There were 1,553 patients $(74 \%)$ who stopped at least one medication, and the most common medication classes to be stopped were alimentary tract and metabolism agents, nervous system agents, blood and blood-forming agents, and cardiovascular agents. The mean number of new starts and stops decreased to less than one medication per person after 90 days of follow-up and remained constant thereafter.

\section{Discussion}

We found that in the first 90 days after an episode of CAP, the prevalence of polypharmacy within our cohort increased from $45 \%$ to $74 \%$, and remained above $70 \%$ for up to 365 days, irrespective of antibiotic use. Although the prevalence of medication classes remained stable during the

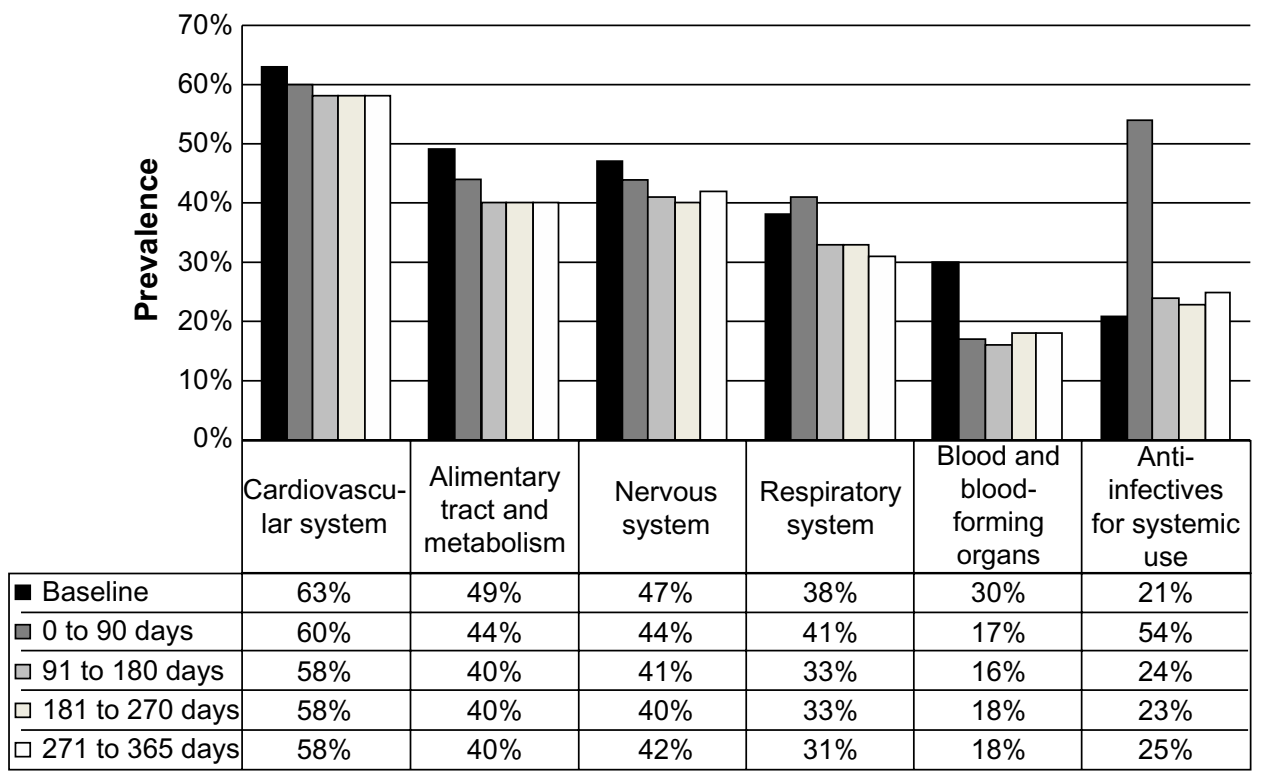

Figure 2 Prevalence of drug dispensations over time for the most prevalent anatomic therapeutic chemical (ATC) level I classes at baseline. 


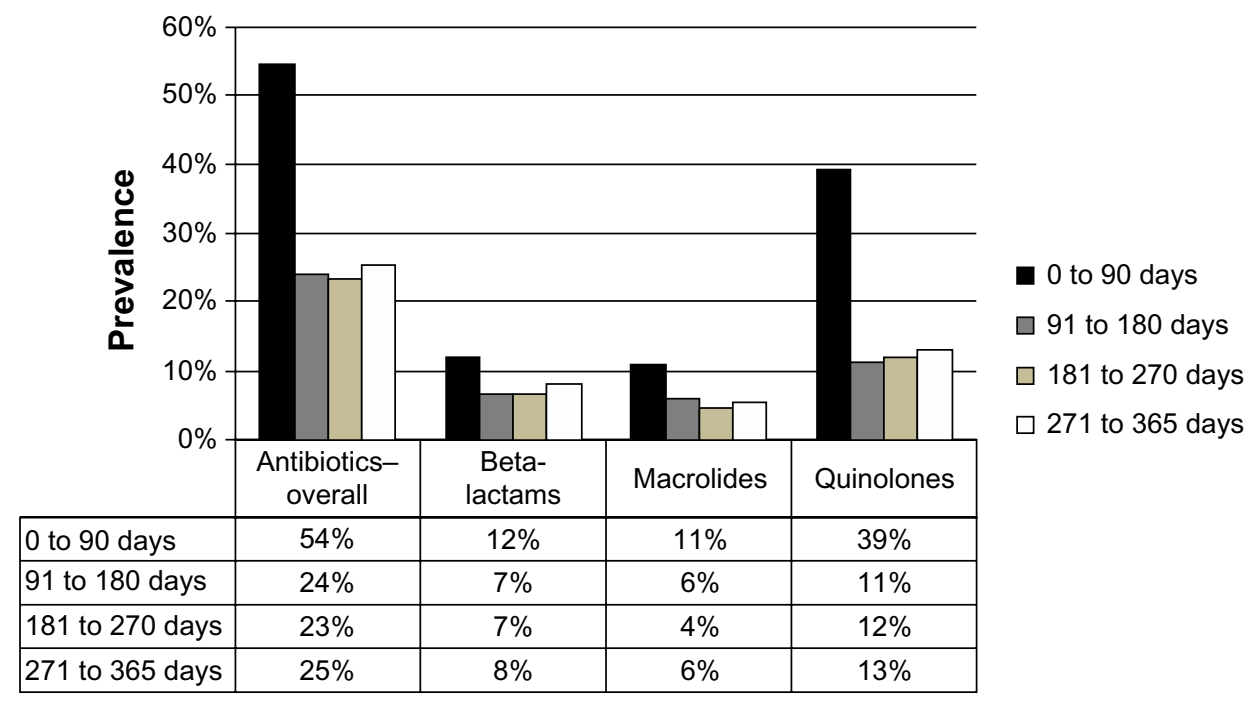

Figure 3 Prevalence of antibiotic use.

1-year follow-up period, it was common for new medication starts and stops to occur within each class, especially within the immediate transition-of-care period (ie, within the first 3 months of follow-up). Interestingly, after completing an antibiotic course that was plausibly connected to the initial episode of pneumonia, fully a quarter of patients were using another anti-infective agent within 1 year.

Others have reported increases in the average number of medications and prevalence of polypharmacy in older adults following admission to an acute care hospital for any reason in the range of $48 \%-62 \% .^{13,19}$ To our knowledge, this is the first study reporting the prevalence of polypharmacy over time in a cohort of older adults, all of whom presented to medical attention with a single condition. We found nearly $75 \%$ of patients used five or more prescription medications following CAP, which is consistent with other studies that have measured polypharmacy rates in sicker populations, such as those living in a nursing home ${ }^{13,16,19}$ or those with diabetes. ${ }^{15}$ We found the use of cardiovascular, alimentary and metabolic, nervous system, and respiratory medications was relatively stable throughout follow-up, and the high prevalence of these medications is consistent with previous studies and reports. ${ }^{13,17,19,29}$

Important changes in medication use were observed in the months following discharge, with both new medication starts and stops being most prevalent in the initial 90-day follow-up period and declining thereafter. The time frame immediately following discharge appears critical, particularly in older adults with multiple medications, where the transfer of care, resolution of acute illness, new medications, and challenges with adherence may combine to produce a higher risk of medication-related problems. ${ }^{13,17,19,30}$ However, we also observed new medications starts in over a quarter of the population and medication discontinuations in over $10 \%$ of the population up to 1 year following their initial CAP episode. The ongoing increase from baseline in the use of antibiotics is particularly remarkable. Although consistent with previous reports, ${ }^{31,32}$ an annual course of antibiotics in a quarter of the population has important implications with respect to community-wide resistance patterns and potential need for better antibiotic stewardship. ${ }^{32}$

There are several limitations of our study. First, the measure of medication use in the week prior to their episode of CAP was based on patient self-report of medications (collected and verified by trained nurses in consultation with patients, proxies, pharmacies, medical records, and medical offices to capture current medication use accurately), whereas medication use during follow-up was measured using dispensing records from administrative data. However, in prior studies from this jurisdiction, self-report of cardiovascular, diabetes, and osteoporosis-related medications has been $90 \%-100 \%$ accurate when using the dispensing pharmacy as the reference standard. ${ }^{33,34}$ Moreover, given that medication use for several chronic disease medication classes (ie, cardiovascular and respiratory medications) did not substantially change and in fact was higher at baseline suggests that recall was not an issue.

Second, the administrative database does not capture over-the-counter medications, such as aspirin or lower-dose histamine-2 blockers, and our data likely underestimate the total number of medications being used. Third, due to the absence of information on the instructions for use, we were unable to quantify more thorough measures of medication 
burden, such as the medication regimen-complexity index, ${ }^{35}$ and could not assess medication appropriateness. It follows that not all polypharmacy is inappropriate; however, it is important to assess the medication regimen rigorously and ensure each medication has an appropriate indication, and is efficacious and safe for the patient.

In summary, we found that $80 \%$ of patients started and $74 \%$ of patients stopped at least one medication class within the first 90 days of their CAP episode, and $75 \%$ of older patients were subject to polypharmacy. This dynamic nature of medication use is particularly worrisome in older individuals who are more prone to adverse drug events, and our findings imply that the postdischarge or convalescent phase of pneumonia in older adults should lead to a thorough medication review with a goal to optimizing and rationalizing drug use while attempting to reduce unnecessary medications.

\section{Author contributions}

All authors contributed to the conception and design, JJH, CAS, JMG, DTE, SRM, TJM contributed to the analysis and interpretation of data, DTE, JMG, JJH, CAS drafted the article, all authors revised it critically for important intellectual content, and all authors provided final approval of the version to be published. All authors had full access to all of the data (including statistical reports and tables) in the study and can take responsibility for the integrity of the data and the accuracy of the data analysis.

\section{Disclosure}

The authors report no conflicts of interest in this work. JMG receives salary support through a New Investigator Award from the Canadian Institutes for Health Research (CIHR) and a Clinician Scientist Award from the Canadian Diabetes Association. DTE receives salary support from the Alberta Heritage Foundation for Medical Research (AHFMR) and the CIHR. SRM receives salary support from the AHFMR and holds an endowed chair in patient health management. Grants-in-aid from Capital Health, and unrestricted grants from Abbott Canada, Pfizer Canada, and Janssen-Ortho Canada have been issued to TJM. All authors declare that DTE, JMG, JJH, CAS, TJM, and SRM have no non-financial interests that may be relevant to the submitted work. The study sponsors played no role in study design or conduct; collection, analysis, interpretation of data; writing of the report; or in the decision to submit the paper for publication.

\section{References}

1. Heron M. Deaths: leading causes for 2008. Natl Vital Stat Rep. 2012;60: $1-94$.
2. Mandell LA, Wunderink RG, Anzueto A, et al. Infectious Diseases Society of America/American Thoracic Society consensus guidelines on the management of community-acquired pneumonia in adults. Clin Infect Dis. 2007;44 Suppl 2:S27-S72.

3. Jackson ML, Neuzil KM, Thompson WW, et al. The burden of community-acquired pneumonia in seniors: results of a populationbased study. Clin Infect Dis. 2004;39:1642-1650.

4. Fulton MM, Allen ER. Polypharmacy in the elderly: a literature review. J Am Acad Nurse Pract. 2005;17:123-132.

5. Cornish PL, Knowles SR, Marchesano R, et al. Unintended medication discrepancies at the time of hospital admission. Arch Intern Med. 2005;165:424-429.

6. Wong JD, Bajcar JM, Wong GG, et al. Medication reconciliation at hospital discharge: evaluating discrepancies. Ann Pharmacother. 2008;42:1373-1379.

7. Bell CM, Brener SS, Gunraj N, et al. Association of ICU or hospital admission with unintentional discontinuation of medications for chronic diseases. JAMA. 2011;306:840-847.

8. Spinewine A, Schmader KE, Barber N, et al. Appropriate prescribing in elderly people: how well can it be measured and optimised? Lancet. 2007;370:173-184.

9. Forster AJ, Murff HJ, Peterson JF, Gandhi TK, Bates DW. The incidence and severity of adverse events affecting patients after discharge from the hospital. Ann Intern Med. 2003;138:161-167.

10. Forster AJ, Clark HD, Menard A, et al. Adverse events among medical patients after discharge from hospital. CMAJ. 2004;170:345-349.

11. Qato DM, Alexander GC, Conti RM, Johnson M, Schumm P, Lindau ST. Use of prescription and over-the-counter medications and dietary supplements among older adults in the United States. JAMA. 2008;300:2867-2878.

12. Veehof L, Stewart R, Haaijer-Ruskamp F, Jong BM. The development of polypharmacy. A longitudinal study. Fam Pract. 2000;17:261-267.

13. Wawruch M, Zikavska M, Wsolova L, et al. Polypharmacy in elderly hospitalised patients in Slovakia. Pharm World Sci. 2008;30: 235-242.

14. Jörgensen T, Johansson S, Kennerfalk A, Wallander MA, Svärdsudd K. Prescription drug use, diagnoses, and healthcare utilization among the elderly. Ann Pharmacother. 2001;35:1004-1009.

15. Huang ES, Karter AJ, Danielson KK, Warton EM, Ahmed AT. The association between the number of prescription medications and incident falls in a multi-ethnic population of adult type-2 diabetes patients: the diabetes and aging study. J Gen Intern Med. 2010;25:141-146.

16. Chan DC, Hao YT, Wu SC. Characteristics of outpatient prescriptions for frail Taiwanese elders with long-term care needs. Pharmacoepidemiol Drug Saf. 2009;18:327-334.

17. Linjakumpu T, Hartikainen S, Klaukka T, Veijola J, Kivela SL, Isoaho R. Use of medications and polypharmacy are increasing among the elderly. $J$ Clin Epidemiol. 2002;55:809-817.

18. Gnjidic D, Hilmer SN, Blyth FM, et al. Polypharmacy cutoff and outcomes: five or more medicines were used to identify communitydwelling older men at risk of different adverse outcomes. $J$ Clin Epidemiol. 2012;65:989-995.

19. Corsonello A, Pedone C, Corica F, Incalzi RA. Polypharmacy in elderly patients at discharge from the acute care hospital. Ther Clin Risk Manag. 2007;3:197-203.

20. Onder G, Pedone C, Landi F, et al. Adverse drug reactions as cause of hospital admissions: results from the Italian Group of Pharmacoepidemiology in the Elderly (GIFA). J Am Geriatr Soc. 2002;50:1962-1968.

21. Flaherty JH, Perry HM 3rd, Lynchard GS, Morley JE. Polypharmacy and hospitalization among older home care patients. J Gerontol A Biol Sci Med Sci. 2000;55:M554-M559.

22. Marrie TJ, Wu L. Factors influencing in-hospital mortality in community-acquired pneumonia: a prospective study of patients not initially admitted to the ICU. Chest. 2005;127:1260-1270.

23. Eurich DT, Majumdar SR, Marrie TJ. Population-based cohort study of outpatients with pneumonia: rationale, design and baseline characteristics. BMC Infect Dis. 2012;12:135. 
24. Fine MJ, Auble TE, Yealy DM, et al. A prediction rule to identify lowrisk patients with community-acquired pneumonia. New Engl J Med. 1997;336:243-250.

25. Quan H, Bing Li L, Saunders L, et al. Assessing validity of ICD9-CM and ICD-10 administrative data in recording clinical conditions in a unique dually coded database. Health Serv Res. 2008;43: 1424-1441.

26. Johnstone J, Eurich DT, Majumdar SR, Jin Y, Marrie TJ. Long-term morbidity and mortality after hospitalization with communityacquired pneumonia: a population-based cohort study. Medicine. 2008;87:329-334.

27. Thomas EJ, Brennan TA. Incidence and types of preventable adverse events in elderly patients: population based review of medical records. BMJ. 2000;320:741-744.

28. WHO Collaborating Centre for Drug Statistics Methodology. ATC/ DDD index 2014. 2014. Available from: http://www.whocc.no/ atc_ddd_index. Accessed January 23, 2014.

29. Garcia-Caballos M, Ramos-Diaz F, Jimenez-Moleon JJ, BuenoCavanillas A. Drug-related problems in older people after hospital discharge and interventions to reduce them. Age Ageing. 2010;39: $430-438$.
30. Canadian Institute for Health Information. Health Care in Canada, 2011: A Focus on Seniors and Aging. Ottawa: CIHI; 2011. Available from: https://secure.cihi.ca/free_products/HCIC_2011_seniors_report_ en.pdf. Accessed September 28, 2012.

31. Mamdani M, McNeely D, Evans G, et al. Impact of a fluoroquinolone restriction policy in an elderly population. Am J Med. 2007;120: 893-900.

32. Zhang Y, Steinman MA, Kaplan CM. Geographic variation in outpatient antibiotic prescribing among older adults. Arch Intern Med. 2012;172: 1465-1471.

33. Majumdar SR, Tsuyuki RT, McAlister FA. Impact of opinion leaderendorsed evidence summaries on the quality of prescribing for patients with cardiovascular disease: a randomized controlled trial. Am Heart J. 2007;153:22. e21-e28.

34. Majumdar SR, Johnson JA, McAlister FA, et al. Multifaceted intervention to improve diagnosis and treatment of osteoporosis in patients with recent wrist fracture: a randomized controlled trial. CMAJ. 2008;178:569-575.

35. Mansur N, Weiss A, Beloosesky Y. Looking beyond polypharmacy: quantification of medication regimen complexity in the elderly. Am J Geriatr Pharmacother. 2012;10:223-229.
Therapeutics and Clinical Risk Management

\section{Publish your work in this journal}

Therapeutics and Clinical Risk Management is an international, peerreviewed journal of clinical therapeutics and risk management, focusing on concise rapid reporting of clinical studies in all therapeutic areas, outcomes, safety, and programs for the effective, safe, and sustained use of medicines. This journal is indexed on PubMed Central, CAS,

\section{Dovepress}

EMBase, Scopus and the Elsevier Bibliographic databases. The manuscript management system is completely online and includes a very quick and fair peer-review system, which is all easy to use. Visit $\mathrm{http} / / / \mathrm{www}$.dovepress.com/testimonials.php to read real quotes from published authors. 